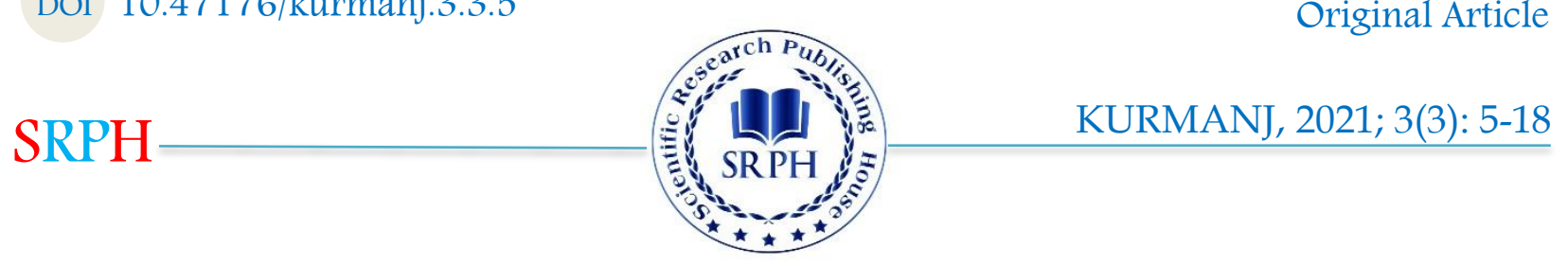

\title{
Errors and Teacher Professional Development
}

\author{
Zahraossadat Mirsanjari ${ }^{1^{*}}$ and Abbasali Aronaghi ${ }^{2}$
}

${ }^{1}$ Khazar University, Iran.

${ }^{2}$ Lecturer, Department of Education of Shirvan, Iran

\section{*Corresponding Author: $\rtimes$ mirsanjaniz@gmail.com}

Received: 20 May, 2021

Accepted: 25 July, 2021

Published: 01 August, 2021

\begin{abstract}
Throughout the world, great change can be observed concerning the role and functions of schools; therefore, expectations of the teachers should also be refined. In this fast changing era, teachers are encouraged to take the responsibility of teaching by reflecting upon their own teaching ideas and practice and initiating necessary changes. This process of reflection, self-monitoring and self-evaluation, though difficult, time- consuming and complex, helps them not to be accustomed to the routines and to engage in the process of professional development. In accordance with the process of teacher development, the present study aimed at examining experienced Iranian high school teachers' ideas and beliefs on errors and error correction to look for any trace of professional development based on their refection and self-evaluation. The teachers were interviewed and their answers were analyzed. The result indicated a kind of change in teachers' perception regarding errors. This change ranged from negative view that considers errors as great sins of the learners in the beginning years of teaching towards a positive view of errors as signs of development and creativity in the process of learning a foreign language after many years of teaching experience. Based on the teachers' answers, it can be inferred that the reaction of the teachers to learners' errors has also changed. In many cases, the teachers provided reflective answers and discussed why and how their ideas about errors and their manner of error correction have changed. The trend of development and professionalism were thus traceable in their reflective writing.
\end{abstract}

Keywords: Errors, Error correction, Reflection, Teacher professional development

\section{Introduction}

In the post-method era, teachers are encouraged to take the responsibility of their own classes and whatever is related to their own teaching. However; for them to be successful and effective, it seems reasonable to think and act consistently. The problem is that sometimes what the teachers do in the classroom (their theoriesin-action) is not according to what they actually believe (their espoused theories). This discrepancy is sometimes unnoticed by the teachers. The notion of increasing self-awareness through the process of critical reflection was suggested by educational scholars to help teachers notice the mismatch (Boud, Keogh, and Walker, 1985). As Schön [1] mentioned the aim of this approach is to enable teachers to become reflective practitioners in order to take time to think critically about their own teaching practices and their worldview about the nature of learning and teaching.

The process of critical reflection can cover a vast area of not only pure knowledge (i.e. the beliefs about the nature of teaching and learning) but also practical consideration (for instance, how to evaluate a particular teaching practice). And exactly that's where a teacher can trace and ponder about the match or mismatch between his/her espoused beliefs and practice.

Through some directed questions the teachers in this study were encouraged to take a deep glance and reflect upon their teaching beliefs about the errors the learners make during the process of language learning. 


\section{Litrature Review}

In this part, the theoretical background of the core themes of the study will be discussed along with the empirical contributions of the researchers who worked on the issues. Since the study concentrates on professional development of teachers in the field of errors and error correction, this section is divided into two parts. The first part discusses the recent description, nature, and research in the area of teacher professional development. The second part presents the current discussions and studies done on the area of errors and error correction.

\section{Part One: Teacher Professional Development}

The distinction between professional development and teacher development are not so marked in the literature. Generally, it can be claimed that professional development is carrier- oriented and has a narrower, more instrumental and utilitarian remit. Teacher development is more inclusive of personal and moral dimensions. In this way, teacher development is actually seen as individual moral commitment [2].

One distinction that is worth exploring is between professional and personal development. The personal development includes dimensions of values, morals and ethics. Johnston [3] discusses the role that values play in language teaching. His aim was to raise language teachers' consciousness of their personal values and specify how these were related to the decisions they make concerning their teaching. Mori [4] explored constructions of personhood. She believed teaching is not a simple technical responsibility and has inherent personal, ethical, as well as moral dimensions. In exploring this moral dimension to teaching, writers such as Edge [5] considered how language teaching is related to the political and global functions of the language being taught. This view traces relationship between large scale events at global level and individual development.

Edge [6] described how continuing professional development brings together very different contributions at different levels: self-development perspective, the management perspective, and the professional body perspective. Edge [7] widened the professional body perspectives further to include teachers, trainers, educators, applied psychologists, administrators, and managers.

\section{Core Themes of Professional Development}

Language teacher professional development

- is a bottom-up process;

- values the insider view rather than the outsider view;

- is independent of the organization but often functioning more successfully with its support and recognition;

- is a continuing process of articulating an inner world of conscious choices made in response to the outer world of teaching context;

- can be encouraged and integrated in education programs [8].

Due to the crucial importance of reflection in the process of teacher professional development, it will be discussed in the following part; since it is believed that any professional development is the result of selfreflection and evaluation.

Reflection

Reflection in teaching refers generally to teachers learning to subject their own beliefs of teaching and learning to a critical analysis and to take more responsibility for their actions [10]. Apart from this, other definitions have been provided. For example, Van Mane [11, p. 25] defines reflection as "the process by which teacher engages in aspects of critical thinking such as careful deliberation and analysis, making choices, and reaching decisions about a course of action related to teaching". Dewey [12, p. 40] argues that reflection comprises several steps:

"1- doubting and feeling perplexity in relation to a given situation;

2- tentative interpreting of the possible meanings of the situation or factors involved in it and their consequences;

3- examining/exploring/analyzing all considerations that might help clarify the problem;

4- elaborating the preliminary hypotheses and

5 - deciding a plan of action."

Van Manen [11, p. 34] discussed "such reflection steps make up reflective experience which in turn can lead to analysis and evaluation, then to further reflective action."

It should be noted, though there are different conceptions of reflection, there is a general agreement on the importance of actively and carefully examining one's own thoughts in order to improve and to develop one's teaching practice [13].

The concept of reflection was originally developed by Schön [1] in his influential book The Reflective Practitioner, published in 1983. Schön [1] introduced and differentiated between two types of reflection: reflection -in- action and reflection -on- action. Reflection-on-action refers to the thinking about the lesson before, as well as after the lesson. However, reflection-on-action refers to the thinking that occurs during the act of teaching. Schön asserted "some of the most interesting examples of reflection in action occurs in the midst of a performance" and can be described in by "phrases like thinking on your feet, suggesting... that we can think about doing something while doing 
it" [1, p. 54.] He believed that each individual's which they act, such that "our knowledge is in our action" [1, p. 49].

We do not necessarily have to stop and think about how to act appropriately as teachers in any situation before we take on action. When we think on our feet or make spontaneous decisions about how to act, then we can be seen as reflecting-in-action, which in turn gives rise to the application of theories-in-action. It is such theories, according to Schön, rather than externally imposed knowledge or theories from elsewhere, which underpin each professional's own unique way of working [14].

The task of the reflective practitioner is to make this tacit or implicit knowledge explicit by reflecting-onaction i.e. by constantly generating questions and checking the emerging theories with his/her personal past experience [15]. Since the assumption is that by thinking about one's actions and reactions while teaching, the teachers can improve their teaching practice.

In short, it can be stated that reflection is a process of inner dialogue and 'conversation with self [16] and in this cognitive space the language teachers develop awareness of practice. Awareness is the outcome of reflexive dialogue between knowledge and experience and can happen individually and collaboratively (Bolton, 2002).

\section{Part Two: Errors and Error Correction}

In this part, the theoretical aspects of errors and error correction will be discussed, and the studies that were done on the issue will be reviewed.

Error correction is one of the major areas of language pedagogy. The teachers' thoughts and beliefs about errors will affect the way he/she will treat them in the classroom. For a reflective teacher not only it is important to investigate when and how the errors should be corrected, but also it is crucial to look at how the learners react to the corrections.

Generally, the word error and mistake are considered to be synonymous, but Ur [17] made a distinction between these two terms. She believed that errors are consistent and based on mis-learned generalizations. On the other hand, mistakes are occasional, inconsistent slips. According to Brown [18], a mistake refers to performance error, which is made by language learners while producing a known structure incorrectly and comes out of through a slip of a tongue. He also referred to mistakes as some sort of unsystematic guesses. Mistakes can be self-corrected, while errors cannot be corrected by the speaker because errors occur due to speaker's language incompetence.

As language teaching history witnessed the rise and fall of language teaching methods one after another, the role of errors and error correction has also changed greatly in each method. However, only in knowledge is mainly tacit and implied by the ways in communicative language teaching (CLT) the errors were not regarded negatively. CLT leads to a positive view regarding errors and error correction in the history of language teaching and learning. The negative view towards errors were finally replaced by the idea that actually, the errors indicate that the learner is in the process of learning, and no learning can occur without making some kind of errors. Therefore, not all errors should be corrected, since they are natural outcomes of development of linguistic and communicative skills. In this sense, second language learning is similar to first language acquisition. "Learning to swim, to play tennis, to type, or to read all involve a process in which success comes by profiting from errors, by using errors to obtain feedback from the environment and with that feedback to make new attempts that successively approximate desired goal" [18, p. 304]. According to Brown [18] people learn language through trial and error. So, it is natural that learners make errors while they learn the second/foreign language, as they do in their first language acquisition.

Reasons for Errors

Learners make errors at various stages of language learning for different reasons. Sometimes errors are due to transfer from their first language. This may happen both at vocabulary as well as grammatical structures. These kinds of errors are called interlanguage errors. There are also some errors that may occur because of grammatical dissimilarities between learner's first language and the second language. For example, Japanese students learning English frequently have problems with article usage [19].

Harmer [20] pointed out errors are not only made for the interference of mother language, but there can be some developmental errors as well. Learners sometimes overgeneralize rules, such as using 'ed' for irregular verbs. In this light, these kinds of errors which are termed interalanguage errors (they can also be found in first language acquisition) should not be considered negative since they point out that learners are actually participating actively in the language learning process.

Feedback to Errors

Richards and Lockhart [21] proposed giving two types of feedback on errors: feedback on content and feedback on form. Feedback on form covers vocabulary, pronunciation, or grammatical errors. On the other hand, feedback on content concentrates on other aspects of errors such as the appropriateness of the utterances.

\section{Teachers' Beliefs on Errors and Error Correction}

Teachers' beliefs are one of the important aspects that influence their practice. Borg [22] defined teacher beliefs as a set of consciously or unconsciously held 
propositions that serve as a reflective guide to the have investigated teachers' beliefs and perceptions about error correction.

Hyland and Anan [23] investigated the effects of first language and experience on teachers' attitudes concerning error correction. The participants of the study were divided into three groups each containing 16 members: (1) a group of L2 English speaking teachers (2) a group of L1 English speaking nonteachers, and (3) a group of L1 English speaking teachers. All participants were given a 150 -word text and were asked to evaluate the text holistically, to identify and also correct the errors. They were also asked to select and rank the most serious errors and to give reasons for their choices. Then, the participants were asked to complete a questionnaire which gathered biographical data and their beliefs about errors and error correction. Results indicated although all participants considered error correction as a positive pedagogical strategy, they performed the task in different ways. Teachers with different experiences contextualized error correction in different ways and this determined their judgments about acceptability in L2 writing.

Perhaps one of the most noteworthy studies in teacher beliefs and practices was conducted by Lee [24] outlining ten mismatches between teachers' beliefs and written error correction practice. Lee reported on the findings from a study that investigated the teachers' beliefs and practice in written feedback from two sources: (1) feedback analysis based on written texts collected from teachers with follow-up interviews and (2) a survey comprising a questionnaire administrated to teachers with follow-up interviews. She elicited the beliefs that underlie teachers' practices in order to help identify the factors that contribute to effective feedback. The key finding of this study is that while teachers tend to correct and locate errors for students, they actually believe that through teacher feedback students should learn to correct and locate their own errors. This demonstrated a mismatch between the teachers' beliefs and practices suggesting that teachers' written error correction practice may not allow students teachers' thought and behaviors. However, few studies to learn how to locate and correct their own errors, even though they believe that it does.

Along with the studies done on teachers' beliefs about different aspects of error correction, the present study aims at tracing professional development of experience teachers concerning errors and error correction through an investigation on their interview answers. Different aspects of the study will be discussed below.

\section{The Study}

The present study deals with professional development of experienced teachers on the area of errors and error correction. The objective of the study is to investigate whether the experienced high school teachers went through a professional development on the nature of errors and how to deal with them in their classrooms. In this study, the theoretical as well as practical aspects of errors and error correction were both emphasized. Thus, the research question of the study is: Did Iranian experienced high school teachers participating in this study go through some sort of professional development in the area of errors and error correction?

\section{Participants}

The participants are three high school teachers who live and teach in a small beautiful northern city of Iran, Babolsar. They are all experienced in a sense that none of them have less than twenty years of teaching experience. One teacher was retired but still teaches English in language institutes and has more than 30 years of teaching experience. Two teachers are still working in schools. All teachers had studies English as their academic major in university. Due to research ethics, from beginning of study, they were informed that they are participating in a research on errors and error correction and their agreement for conducting the study based on their interview was achieved. But it was tried not to give them any hint on the main focus of the study that is professional development, since it was supposed that knowing this point will affect the teachers' answers. The information about the participants is summarized in Table 1 below.

Table 1

Educational and career information of the participants

\begin{tabular}{lclc}
\hline & Years of teaching experience & Academic major and degree & Sex \\
\hline Teacher 1 & 32 & B. a. in English language and literature & male \\
Teacher 2 & 20 & M. a. in TEFL & female \\
Teacher 3 & 20 & B. a. in English language and literature & female \\
\hline
\end{tabular}

\section{Materials}

The materials of the present study consist of the teachers' answers to the interview questions.

\section{Procedure}

Professional development is so complex and comprehensive that no study can investigate all of its 
aspects. Therefore, in order to narrow down the focus of the study, it was decided to work on one aspect of development in this aspect. As it is mentioned in pervious section, professional development is both theoretical and practical in nature. So, in order to investigate the practical aspect of the issue, the teachers' manner of error correction was also added to the focus of the study.

The instrument that was chosen for the present study was structured in-depth interview with the participants in order to elicit their ideas, beliefs, and knowledge about errors and to study how the teachers actually deal with learner's errors in their classes. Therefore, some questions focused on theoretical assumptions of teachers about the issue and some were on practical aspects (see appendix).

Since the answers to the interview questions required a great deal of reflection and self-evaluation, the questions were typed and given to the teachers to study and answer them at home. It was assumed this procedure would assist the teachers to provide more trustworthy answers. After three days the answers were collected.

\section{Results}

Since the focus of the study is to trace professional development of teachers in theoretical as well as practical aspect of errors and error correction, this section will be divided in three sections: section one will focus on theoretical aspects of error and what teachers know and believe about the nature of errors. Section two deals with practical aspect of errors and how the teachers actually deal with errors in their classes; and section three looks for any connection between knowledge about errors (section one) and practice (section two) and thus, it is tried to trace some sort of professional development.

\section{Section One: Theoretical Aspects of Errors}

In this part, the participants' ideas and beliefs about the nature of errors, sources of errors, and positive and negative ideas about errors will be investigated.

The first question of the interview asks 'What are errors?'. Through this question, it was desired to elicit teachers' ideas about the nature of errors.

Teacher 1 (T.1) answered: "The language learning is a process that necessarily involves errors. As children and adults are exposed to samples of language, they often have hypothesizes about language. Sometimes errors are because of faulty and incomplete knowledge of the target language."

It seems T.1's primary attention in answering this question is on interalanguage errors, the errors that are due to the process of language learning.

Teacher 2 (T.2) wrote: "Errors are incorrect words or forms that a learner uses in his/her performance. teaching - errors - and to pursue professional

Errors can be related to different parts of a language. They can be errors of grammar, meaning, pronunciation, spelling, etc.,.... Errors usually have a pattern. It means that the learner repeats his/her error in the same way."

T.2 first describes different forms of errors and then implicitly differentiates errors from mistakes by stating that errors have patterns and are repeated by the learner in the same way and are not randomly produced like some mistakes. What is important here is that this teacher did not focus on the causes of errors. In this way, it seems that the T.2 just accepted errors as a usual phenomenon without looking for why they usually happen.

Teacher 3 (T.3) answered: "Errors are getting away from the correct or precise pronunciation of a word, utilizing a structure, or fathoming on the issue unconcisely. Despite the fact that we have learnt an issue, we mispronounce a word or misuse a structure undeliberately."

Again there is no mention of interlanguage errors. Here, just incorrect application of previously learned forms is assumed to be the cause of errors.

The second question of interview focuses on the sources of errors. The prominence of knowing the sources of errors is because it will affect on the reaction of the teachers in dealing with them.

T.1 wrote: "There are many sources for errors:

a. the errors the source of which are in the target language and are called interlingual errors. This kind of error is caused by overgeneralization of the target language. Like when a child learns "sang" for the past tense of sing, he then thinks he must say "brang" for the past tense of bring.

b. There are some errors that their source is the native language like, when a student says "student good" instead of "good student".

It seems T.1 is well aware of the interalangauge and interlanguge errors, though he did not mention interlangauge errors in his answer to the first question. His answer is very much like the linguistic books dealing with L2 learning theories and thus, it can be assumed his knowledge about this issue may be rooted in such books. Of course, his second example "student good" shows that this book knowledge was contextualized with his experience with Iranian students. So, here we can see knowledge and experience merged and each supports the other.

T.2 answered: "There are several sources. One of them is lack of knowledge. Second one can be L1 influence on L2 or L1 interference. For example, in Farsi, verb is the last element of the sentence but in English it comes after the subject. So, it is not unusual if an Iranian learning English says "I in Mashhad was.". The third source of errors can be a learner's generalization of a 
rule or intralingual errors. For example a learner may say "He drinked.".

Like T.1 it can be assumed T.2's experience is combined with the knowledge she has learned in her academic courses.

T.3 wrote: "Errors would happen by one of the following factors:

- attending to deep structure rather than surface structure

- close similarities between the words in spelling

- student's endeavor to survive

- losing concentration

- lack of self-esteem

- absence of sufficient knowledge

- overgeneralization."

T.3 made no formal classification for the sources of errors. She just tries to find the sources for some of the cases she remembers of her learner's errors. But the important point in her answer is that three out of seven sources of the errors she mentioned are due to emotional states of the learners, the point that was not mentioned in the answers of other teachers. This may imply that for T.3 emotional aspect of the learning is as important as intellectual states.

The eighth question which is the last question on theoretical aspects errors, the teachers were asked: 'Which one do you believe in? Please explain.

a. Errors show insufficient knowledge and must be corrected whenever they occur.

b. Errors are signs of development.'

T.1 preferred the first one and provided no explanation. His answer is in contradiction with his previous answer that he stated that some errors are interalanguage in nature. If errors are natural outcome of a learning process, they may not indicate insufficient knowledge. They may actually show how the learner tries different forms to convey what $\mathrm{s} /$ he means.

T.2 wrote: "I believe in $\mathrm{b}$ and the first part of a. i.e. errors show insufficient knowledge. I think errors are signs of creativity. For example, when a child starts to speak he/she may use the words incorrectly. He uses words according to his limited vocabulary knowledge. For example, he/she may say "The book is fat." Instead of saying "The book is thick.". This shows the creativity. Actually the child doesn't repeat the sentences she or he has learned. He tries to create some new ones although they are not correct. In the same way, a learner also tries to use new structures and terms instead of repeating some fixed or heard sentences. So, errors are inevitable during the learning process."

It seems T.2 has a good knowledge of errors, combined by her experience on how children learn their first language. She has two sons and told me she paid careful attention on how her children learned to speak.
This helped her to contextualize her knowledge, the point that is apparent in her examples.

T.3 wrote: "I agree with b. Errors happen in the acquisition of L1 \& L2. So, it indicates relative development and improvement in the process of completing one's knowledge."

T.3's answer indicates that for her errors are not negative and can be regarded as positive signs of linguistic development.

Section Two: Practical Aspects of Errors

Practical aspects of errors or how the teachers deal with errors as they stated in their interview will be discussed in this part. Questions 4, 5, 6 and 7 deal with this issue. In question four, the teachers were asked: 'Should all errors be corrected?

If yes, how? If no, which error should be corrected and how? Which ones should be ignored and why?'

T.1 wrote: "It is better to do the best and to correct all errors. It involves using the best methods of learning from primary school. Learners should know that learning a language correctly is an essential need."

T.1's answer seems to be the first answer one can provide for such question. Actually, there are many aspects in correction that a teacher should consider while deciding to correct or to ignore an error. Some of them are mentioned in T.2's answer coming below.

T.2 answered the question in this way: "No. they shouldn't. The following errors should be corrected;

- the errors that block communication.

- the errors that are related to several previous levels for example, an intermediate learner makes an error related to beginners.

- Errors that mislead other learners.

Errors can be corrected implicitly or explicitly. Errors that are not often repeated or don't interrupt or block communication should be ignored. In my opinion, the type of performance is important in correction, as well. For example, in writing and reading, errors should be more often corrected than speaking. The most ignorance should be in speaking and pronunciation. I think the age and level of learners are determining elements in error correction and ignorance. Beginners and children should be explicitly corrected."

T.2 paid careful attention to different aspects of error correction: which errors should be corrected and which ones should not, which criteria should be chosen for correction and ignorance, implicit and explicit error correction, which modes of language require more correction, and paying attention to age and level of learners in correcting them. The points made by this teacher indicate she had reflected on different aspects of error correction during her teaching.

T.3 wrote: "Error correction is so crucial in a language atmosphere; in a case that we should highly care neither neglect our burden of teaching the target language 
correctly, i.e. teaching correct use of structures, sentences, vocabs, functions, expressions, etc., nor and interrupting them. Since we interrupt the train of their thoughts in speech, we would cause the learners to lose their confidence. As a teacher, if I want to be secured of harms of improper error correction, we need to develop a good relationship with the learners and increase their linguistic self- confidence. ... Therefore, in the following cases, the error correction can be ignoredor delayed:

- when we aim to motivate the learner to learn the target language.

- When we need the learner's cooperation \& interaction in the process of teaching.

- When cognition is more important than word order in the sentence.

- When the aim is just communication, it is suggested that we don't interrupt the learners to correct their errors, but let them continue to express themselves. In this case the teacher can delay error correction after speech.

- In group discussions in the classrooms, it's better not to interfere by error correction; instead, it is better to do it after the discussion.

- When we want to motivate our students to read a text and enjoy it."

Though T.3 is well aware of the importance of error correction, she is very much concerned with the humanistic side of language learning, the point that she had previously implied in her answer to question number 2. There are many cases that she prefers not to correct her students in order not to demotivate them or unintentionally decrease their self- confidence in in the process of language learning. Based on what she wrote, it can be assumed she is sensitive to the emotions of the learners in the process of learning and is careful not to have negative influence on her learners.

Questions 5, 6, and 7 deal with other practical aspects of error correction.

'5. Do you think learners want their errors to be corrected? How do you know that?

6. Do you think learners will learn from error correction? How? When error correction is most helpful for them?

7. Which one do you prefer and use most? Implicit or explicit error correction. Why and why not the other one?'

In these questions, it was tried to check whether the teachers pay attention to the learners and to the effect of error correction on them, to see whether they evaluate their manner of error correction not just based on what they read in books, but actually based on what they observe and feel in the classrooms. In the seventh question, the diversity in error correction was put into focus. It was desired to check whether the teachers stick to just one type of error correction or consider the demotivate our learners by consistent error correction

situation and choose the best alternative that best suits the context.

T.1 answered the fifth question in this way: "Yes, I think they want their errors to be corrected. Many of them try to use the correct language by involving more activities through listening, reading and participating in further classes."

For sixth question he wrote: "Yes, I think learners will learn from error correction when the teacher helps them to use correct language and they get better results. The teacher should know and evaluate his learners and use the best way of error correction to help them. It depends on the learners and class situation."

And for the seventh question, he wrote: "I prefer to use explicit error correction. Because by explicit error correction the learners get better results and soon make correct their errors. But implicit error correction takes a lot of time."

T.1 is aware of the importance and effect of error correction on his learners. Although his answer to the seventh question reveals time limitation and short-term achievement of the learners forced him to prefer explicit error correction to the implicit one.

T.2 answered the fifth question in this way: "I think beginners and intermediate (children) learners don't like to be corrected. Because the grades and marks are more important for them rather than learning. But adults, upper intermediate and advanced learners welcome error correction because they want to have a more accurate and native-like performance."

The sixth question was answered: "Yes, I think learning from error correction needs time and repetition. I mean a teacher shouldn't expect a learner to correct his/her errors in a short time by only one or two times error correction by his/her teacher. Error correction is more helpful for beginners and advanced learners."

For the seventh question she wrote: "I prefer implicit error correction. When I want to grade the learners, I use explicit error correction, because learners are not aware of their errors. When the aim is communication, I use implicit error correction. Explicit error correction may cause the learner to lose confidence and not to be able to continue his/her performance. Explicit error correction is used when communication has blocked. I also prefer explicit error correction for children, beginners, and advanced learners."

T.2's answers to the questions are more reflective. Based on her experience, she has noticed children and beginners are less willing to be corrected, while adults are more willing; even she has thought about the reasons for each of these reactions - looking for good grades in children versus trying to sound native-like for adults. Her answer to the next question shows that she knows for effective error correction, time is crucial and it is not correct to expect good results in short time. 
The diversity in error correction is discussed in her answer to question number 7 and indicates that as a T.3's answered the three questions in this way: "What really happens in the realm of teaching vocabs, in a classroom would be one of these cases while occurring an error:

- The student stumbles on correct pronunciation of a word and the learner attempts to pronounce it or he/she would get help of the teacher or other students.

- When an error happens by a student, some students automatically correct the errors.

- If neither of the above takes place, the teacher would correct the error, considering the affective domains, explicitly or implicitly.

But the situation differs in correcting the errors in a discourse, the peer pressures would usually correct their friend's errors, otherwise, this is the teacher who decides to correct the errors after the discourse or ignore them."

Here, the teacher is describing the picture of classroom when a learner makes an error; her answer is not that much concentrated on the questions asked.

Section Three: Reflection on the Issue of Errors and Error Correction and Tracing Professional Development

As it was mentioned in the first part of the article, professional development is only possible when the teachers get involved in a process of reflection over their experience.

Inquiry, questioning, and discovery are the norms that are embedded in the reflective practitioners' ways of thinking and practice. The inquiry focuses not only on the effectiveness of the instruction, but also on the underlying assumptions, biases, doubts, uncertainties and also values they bring to educational process. Instead of blindly accepting or rejecting new information or ideas, the reflective practitioners carefully examine, analyze, and reframe them in terms of specific context variables, pervious experiences, and alignments with desired educational goals. Reflective practitioners are thus decision makers who develop thoughtful plans to move new understandings into action so that improvements result for learners [25].

Reflective thinking also implies that the teachers should be aware of their belief systems and constantly monitor how far their actions reflect those beliefs or are in line with them. In this process, the teachers are engaged in a multilevel process of action, monitoring, reflection, feedback and further action. Thus, to be a reflective teacher requires looking both inwards and outwards. The teachers need to develop their awareness of other's viewpoints, in this case different perspectives on teaching, and to look to their own beliefs, standards and values. They then need to construct a particular identity of the kind of the teacher they want to be and to seek to reproduce this in their day-to-day activities, professional teacher, she uses different types of error correction in different situations for different learners. in their actions and interactions in the teaching-learning arena [26].

Therefore, reflection involves trying to make the implicit or tacit knowledge explicit by reflecting on action and on personal past experience. Questioning the norms for the effectiveness of the instruction and thinking about the underlying assumptions, biases, doubts, and uncertainties are values that are influential in this process. In the present study, it was tried to insert these aspects of reflection in questions ten to sixteen of the interview. In questions ten and eleven the teachers were asked:

'10. Have you ever thought about your manner of error correction? Explain.

11. Have you ever compared your manner of error correction with other teachers? If yes, what was the result(s)?'

In these questions it was tried to trace some sort of reflection-on-action on the area of errors and error correction.

T.1 answered: "I've always thought of that a lot. We, as teachers commit a lot of inappropriate styles in classroom activities. It occurs that sometimes you rectify a learner, you will see the negative feedback right away. It may even cause your learner to put aside language learning. When you come across such a response, you'll never forgive yourself. Fortunately, if you are flexible enough not to show other negative reactions against his/her negative acts, you can reflect upon this issue and look for better ways in order to correct and at the same time keep the learner interested in learning."

An inevitable part of structured reflection is the recall of particular events in language classroom. Richards (2004) provided a three-part model suggesting specific reflective strategies on particular pedagogic events. He distinguished between the event, the recollection and the review and/or response to the event. Recollection of the event is enhanced by some form of stimulated recall which is a procedure for making visible the invisible and can bring to the surface some of the values and beliefs underpinning a teacher's classroom practice. A related kind of recall which is termed 'critical incident analysis' [27] focuses on 'commonplace events that are critical in the sense that they reveal underlying beliefs or motives' [21, p. 114]. This is what is observable here. T.1 seems to be affected by his learner's negative feedback to his error correction; but the turning point is that when the teacher detaches himself from the instant moment and reflects upon this issue, he makes this learner-teacher unhappy interaction work for him rather than against him "you can reflect upon this issue and look for better ways in order to correct and at the same time keep the learner interested in learning". 
For question eleven, he answered: "That is found out just when you are involved in other teachers' process of minded enough, in special classes when other teachers participate, such objectives can be propounded so that the best manners are selected to be used. You know that is what I achieved during 32 years of teaching. One tries to reject the other, or at least cannot accept critical points on his/her teaching. I wonder why there's such a case. Well, all teachers must be aware that knowledge is infinite. We are finite. So, we are just some drops of the ocean of knowledge. So why should a teacher depict his/her so-called dogmatism? Although those teachers are not that successful to train their learners well, they insist on keeping on their own improper styles."

Here T.1 tries to justify why he is not able to compare his manner of error correction with that of his colleagues in his teaching background. Against him, some other teachers stick to their own manner of teaching and do not welcome other critical points, nor do they try alternative styles. This reality which this teacher felt all over his long period of teaching grieves him. It seems that those teachers become habituated to their teaching in such a way that they cannot accept that there are so many different ways for achieving one goal and may be others' ways function better than theirs. Thinking in this way prevents the teachers to initiate some sort of change in their ideas and behavior and gradually filters professional development.

T.2 answered question ten in this way: "Yes, I have. During the M. a. courses and while cooperating in some researchers' project like the one that I am doing now, I have thought about it more seriously."

And for question eleven, she wrote: "To be honest, no."

T.2's short answers implies that the process of reflection for this particular teacher has started as she declares she has thought about her manner of error correction, but it seems that she needs some sort of motivation to pursue and continue this process such as participating in research projects that promote reflection or regular meetings with colleagues in order to discuss teaching problems.

T.3 answered: "A good teacher is always obsessed not only with new ways of error correction, but also with evaluating and assessing these ways. By considering the results, I can decide which one is suitable for each situation."

T.3 is actually involved in the reflective practice which was previously mentioned; in this process, the teachers are engaged in a multilevel process of action, monitoring, reflection, feedback and further action. This cycle led T3 to come to better understanding and achievements in her process of professional development.

For question number eleven, she wrote: "Not much. I have always tried to be creative in obviating my teaching. I mean it occurs very seldom, that you compare your style with others. But if you are openclassroom problem by myself. In error correction, I usually have been successful.

But if I find no suitable solution, I'll definitely consult with my colleagues. Because I believe that teaching is a very vast issue and also tough because of the complexity of language itself and the personality of the learners."

It seems teaching English did not become a routine in T.3's career life, since she is well aware of the complexity of the language itself and also the learners who are supposed to learn it, willingly or unwillingly. She is also confident enough to rely on her own to deal with her teaching problems, though she does not reject consultation with her colleagues when she cannot find good solutions.

It was mentioned earlier that innovation and change are necessary part of teacher development process [28; 29]. Allwright [30] argued the classroom is a site providing opportunities for experimentation, exploration and change for both teachers and the learners. Prabhu [31] stated some element of change is developmental and is linked to the teacher's developing a sense of plausibility. If teacher becomes over-routinized, increasing detachment and plausibility cannot be engaged [31]. Plausibility is engaged through change, reflection on experience of teaching, and through interaction with other teachers' versions of plausibility. In questions 14,15 , and 16 the element of change was the primary focus.

'14. Do you think your knowledge, belief and ideas about errors and error correction from the beginning years of your teaching up to now has changed? In what ways? Please explain detailfully. You can also write any anecdotes of interesting points you remember about errors and error correction.

15. Why did you change your ideas about this issue? (if there is any change.)

16. Some years later, do you believe you will still hold the same ideas? Why do you think so?'

T.1's answer to question 14 was: "Yes, at the beginning of my teaching I was very sensitive towards the learners' as well as my own errors. But gradually things changed as I changed. For example, when I was teaching my students the phonology and phonetic symbols, I faced something interesting. One of my students told me publicly that I was wrong with pronouncing one word. I asked him to come to the board to prove it. He beautifully wrote the phonetic symbol of the intended word. I was really impressed and happy because my teaching was so effective that even a learner can find out a teacher's error. I didn't lose my temper or felt ashamed, but I became very happy and admired him with a prize."

T.1 like other participants experienced a kind of change in his manner of error correction, from being

Page | 13 
oversensitive to his as well as his learners' errors to the state of tolerance and reflection. The anecdote that he T.1 answered question fifteen in this way: "We must be aware of the current improvements or developments. If we are not updated, we will be behind the new methodologies. For this reason, I have to change my old ideas or old techniques which do not respond positively. That's why I still teach in institutes (after retirement) to stay updated through teaching new methods and interacting with observers and colleagues."

Trying to be up-to-date motivated this teacher not to stop after retirement. This means that the cycle of change and reflection is still moving for him. This fact is also apparent in his next answer coming below.

The last question was answered in this way: "I can't answer this question quite explicitly. Well, for some aspects in teaching the techniques are the same, whether old or new,

e.g. teaching vocabulary. The intended steps should be obeyed. But we must be conscious of the changing world and new necessities, so introducing new steps of teaching should be expected. In short, teachers are obliged to deal with new technology and the authorities should compulsorily provide them with the necessary teaching facilities and compel them to be updated."

T.2 answered question fourteen as: "Yes, to some extent. I think I have a more positive attitude towards the errors now. As a novice teacher, I didn't expect the learners to have errors. I expected them to learn whatever I have taught. Sometimes I blamed myself for their errors. But now I believe errors are part of language learning process. Before I used explicit ways of error correction more than implicit ones. I prefer implicit ways, now. Of course, I believe using implicit or explicit ways of error correction depends on several factors such as age, level, type of activity, aim of activity and even individual differences and personalities.

Once I took part in a T.T.C. session. There was an instructor who talked about error correction and strongly emphasized on implicit error correction. He told a long story on the disadvantages of explicit error correction. After that one of the teachers had had a presentation. During the presentation, she pronounced "live" incorrectly. She said /li:v/ which means 'go away'. The instructor corrected her exactly "on the spot". I mean the first time that she made the mistake or may be the error. He corrected her in such a way as if she had done a great sin. She couldn't continue her presentation."

As T.2 stated she has moved from the traditional view of errors as linguistic sins towards a positive view that accepts errors as part of learning. She has passed the moments when she blamed herself for her learners' errors and entered into the moments of tolerance and acceptance. Now, not only the errors, but also other factors that can affect the learners who make the error narrates above indicates his democratic teaching style and his open mind.

are important for her, such as: learners' age, character, language proficiency level, also the characteristic of the activity which the learners participate in. This transition indicates a sort of professional development that is the result of reflection on the experience.

For question fifteen she wrote: "My own experience and academic studies were important factors in changing or better to say moderating my attitude towards error correction. The above story was an evidence for my own experience. I had taught for ten years before I was accepted in M. a. so, it was a very good time to examine my performance during ten years while I was an M. a. student."

M.a. for T.2 functioned as an opportunity to reflect upon her teaching practice, evaluate it and as she said moderate her ideas and practice. Therefore, change for this teacher is also rooted in her reflection on her teaching.

For the last question she answered: "Yes, I think the basis of my ideas won't change completely but it is possible to moderate the way of my error correction. New findings may influence me."

She thinks change is a non-stopping process and there is no end to it. This helps the teacher to become updated and does not become habituated to the routines. T.3 answered these three questions in this way: "Though a knowledgeable teacher may have read a lot of books and journals about methodologies, we would not be sure of his/her capability of utilizing them in a real atmosphere. As I mentioned above, both language and human being are complex. I think experience speaks louder than theories. I never deny the role of theories, but theories and experience are tied in a firm knot. It is clear that the more you experience, the more you fathom what really teaching mean. And error correction is not an exception. So, naturally by experience one may change his/her ideas about error correction and other issues. These changes may be a sign of improvement in one's profession. A responsible teacher has always challenges about better ways of error correction and other issues in methodology. However, as teachers we have a profound understanding of learners' background and motivation of learning a target language. As far as I have experienced, sharp and motivated students are more willing to learn new things and use their information in the discourse and thus the teacher's error correction would hardly lead the learner to lose his/her motivation in learning the target language. Therefore, in error correction I suggest we should be more careful about the students with weak background, motivation, and the learners who are so irritable or touchy. It is an undeniable fact that the students studying at schools are mostly more affected by their peer-pressure than their teachers. That is in practice, if the teachers' error correction doesn't work, 
the peer pressure's explanations would usually be more perdurable in learners' minds."

deny the role of theories, she thinks that experience is by far more effective in shaping one's perception of reality. There are many aspects of teaching (such as paying attention to learners' motivation or language background) which the theories cannot account for all of them at once, but as a teacher, one is supposed to give her full attention to them all. Reflection and change make it possible for this teacher as well as others to make use of their experience and become able to make use of it in order to improve that is one step forward towards professional development.

\section{Discussion}

In this part, it is tried to make some inferences based on the participant's answers to different aspects of teacher professional development.

\section{Teacher Knowledge and Teacher Development}

Studies such as James [32] offered a breadth of writing on teacher knowledge. This section considers different types of knowledge that informs language teachers' practice. Some of this knowledge is received knowledge [9] and some of it is more of personal or individual nature, and arises from experience and reflection on experience. This section also considers where this knowledge usually comes from, what form it takes and how it maintains a reflexive relationship with development and professionalism. The relationship between teacher knowledge, teacher development, and professional development is the issue that continues to change and needs further examination.

Bowen [33] has demonstrated the enormous range of teachers' ways of knowing. The central question is 'What is knowledge and who holds it?'. Of course, this is a deceptively simple question. What is clear is that knowledge is not in any simple way transferred from educators and trainees to teachers [21]. Knowledge is at least partly constructed through engagement with experience, reflection and collaboration. Its multifaceted nature includes received knowledge, personal knowledge, experiential knowledge as well as local knowledge [9].

\section{Knowledge Organized into Topics}

When knowledge is parceled up, as it is in teacher education programs, the list will be quite varied and extensive. There has long been an understanding that topics such as lexical studies, syntax, semantics, SLA, phonology, discourse analysis, pragmatics, sociolinguistics and psycholinguistics have an important role in the development of teachers' knowledge base [9]. As it is observable in the teachers' answers to the questions, most of their knowledge has rooted in their academic courses and materials. Later,
The answers reflect she is more inclined to make use of her experience than theories. Though she does not when they started to teach, they combined, revised and completed their knowledge on different aspects of teaching especially on errors and error correction based on the realities of the classrooms. This kind of knowledge which is called individual knowledge will be discussed below.

\section{Individual Knowledge}

Recent work on language teaching has witnessed a movement away from a transmission of knowledge framework in which knowledge about teaching and related topics are delivered, towards a view of teacher education as an ongoing engagement between received knowledge and experiential knowledge [34]. This approach draws more attention to the processes of individual development. Loughran [35] discussed a new scholarship that articulates an epistemology of practice that characterizes teachers as legitimate knowers, producers of legitimate knowledge, and as capable of constructing and sustaining their own professional practice over time'.

Greater interest in the individual meant greater consideration of the types of teacher knowledge, rather than seeing knowledge as a series of topics. A description that focuses more on the individual teacher and various constructs of teacher knowledge would include content knowledge, pedagogical knowledge, curriculum and materials knowledge, knowledge about SLA, and knowledge about learners and the context. It would also include personal knowledge, practical knowledge, experiential knowledge, local knowledge, and usable knowledge [30]. There are also other related constructs such as BAK, [22] which considers the interplay between beliefs, assumptions, and knowledge. This interplay between knowledge, beliefs and assumptions is apparent in the teachers' answer to questions 14 and 15 in which the teachers describe how their ideas and beliefs about their learners' errors has changed as they changed during time, and how they achieved a kind of maturity on the issue over time.

There is an obvious overlap between these types of knowledge. For example, local knowledge, or knowledge about the context, recognizes that knowledge is situated and socially negotiated. The local has a reflexive relationship with the existing knowledge. These various metaphorical constructs help us to describe the complex nature of teacher knowledge [36]. The recognition that teachers are constantly reshaping knowledge through the complex interplay between declarative or received knowledge on the one hand, and personal, experiential and local knowledge, on the other hand, means that a full description of any teacher's current knowledge and development needs to take a full account of these constructs. Mann [9] suggested new understanding 'emerges from a process of 
reshaping existing knowledge, beliefs, and practices' and this process of constantly reshaping knowledge knowledge), the teaching context (local and situated knowledge) and the individual (personal, practical and usable knowledge). Although all three teachers' responses revealed cases of these three types of knowledge, for each of them one type was more important and reliable. For example, T.1 more relied on his teaching context which promoted developing local and situated knowledge. T.2, on the other hand, utilized external knowledge (received knowledge and declarative knowledge) and also teaching context (local and situated knowledge). Paying attention to different aspects of teaching and learning as apparent in her answers more than the other teachers is the result of this combination. However, T.3 was more obsessed with the individual (personal, practical and usable knowledge). Therefore, emotional aspects of learning and learners and also initiating and continuing successful interaction with learners were important for her. This fact can be traced in almost all of her answers.

\section{Situated Knowledge Developing over Time}

The recognition that knowledge is complex and not in any simple term transferred from experts to novices means that there has been some interest in how this knowledge is constructed and developed over years of professional practice. Bowen [33] discussed how teachers draw contextually relevant information from their existing knowledge base in detail. This knowledge bases change over time, through the process of teaching and reacting to local influences affect teaching. However, more accounts are needed of how such professional competence develops. Bailey [28] considers the development of language teaching expertise over a period of time and uses some case studies to highlight ways in which different forms of knowledge contribute to growing proficiency. Freeman [15] argued that we need to move from focusing exclusively on what happens in the classroom to focusing on teacher's work as it evolves. She stated teacher educators need to do a better job of not only researching teachers' knowledge bases, but also of helping teachers develop their own situated relationship to disciplines which might expand or contribute to this knowledge base.

\section{Reflection, Exploration and Evaluation}

Richards and Lockhart [21] argued that learning and development to become a professional through teaching is only possible through a process of reflection, self-monitoring and self-evaluation. They see these processes as the only possible basis for long-term change. A process of exploration or investigation in the classroom is often a catalyst for self- evaluation, selfmonitoring and reflection. James (2001) provided a number of procedures for self-monitoring and self- takes place in the cognitive space between external knowledge (received knowledge and declarative evaluation and suggests various forms of lesson reports, checklists and questionnaires for reflective teachers.

The participants of this study can be assumed to be reflective practitioners in the sense that they have thought about different aspects of errors and their manner of error correction. They also reflected on why learners make errors, how they respond to their correction, when error correction is most successful and for what kinds of learners. They have also thought about different factors that affect the process of correction. These considerations require a great deal of reflection, self-monitoring and self-evaluation.

\section{Change as Development}

Innovation and change are necessary parts of teacher development process [28; 29]. The new and the fresh events help to maintain interest in classroom teaching. Allwright [30] argued that the classroom is a site that provides opportunities for experimentation, exploration and change for both teachers and learners. He explored the relationship between professional development and teacher change, and presents a model in which significant change in teachers' attitudes and beliefs occurs primarily after improvements in student learning. Prabhu [31] believes some element of change is developmental and is linked to a teacher's developing a sense of plausibility. If the teacher becomes overroutinized, there is increasing detachment and plausibility that cannot be engaged. Plausibility is engaged through change, reflection on experience of teaching, and through interaction with other teachers' versions of plausibility.

The change in teachers' views about errors was the theme that was observed in all of the teachers participating in the study. This change ranged from negative view that considers errors as great linguistic sins of the learners towards a positive view of errors as signs of development and creativity in the process of learning. Based on the answers, it can be inferred that the reaction of the teachers to learners' errors has also changed. Blaming oneself and feeling uneasy when the learners made errors were replaced by a sense of tolerance and acceptance.

Having discussed different types of knowledge, the non-stopping process of change and development, it can be claimed that all participants of the study experienced change in their ideas and beliefs concerning errors and error correction though on different scales. All of them have reflected upon different aspects of this issue and thus opened the door of professional development. 


\section{Conclusion}

school teachers were interviewed to elicit their ideas about this issue. Then, based on their answers, it was tried to look for any cases of reflection and professionalism. As it was documented in the discussion, in many cases the teachers provided reflective answers and discussed why and how their ideas about errors and their manner of error correction have changed. The trend of development and professionalism were thus traceable in their reflective writing. However, other studies on this issue and other aspects of teaching are needed to shed more light on the complex issue of teaching and to enhance our understanding of teacher development and professionalism.

\section{References}

1. Schön DA. The reflective practitioner: how professional think in action. New York: Basic Books. 1983.

2. Miller P. Review of 'values in English language teaching'. TESOL-EL. 2004; 7(2): http://wwwwriting.berkeley.edu/tesl-ej26/r3.html

3. Johnston B. Values in English language teaching. Mahwah, NJ: Lawrence Erlbaum. 2003.

4. Mori R. Personal growth in teacher development: a case study. In Proceedings of JALT 2003 Conference, Shizuoka. Japan. Tokyo: Japan Association for Language Teaching (JALT). 2003; 155-161.

5. Edge J. The reflexive teacher educator in TESOL: roots and wings. Routledge. 2011.

6. Edge J. Managing professionalism or 'hey, that's my development'. LATEFL Issu. 1999; 149: 12-16. http://www.easy.com/ELT/publications/IATEFLIssues/Archives/ Texts/149Edge.htm

7. Edge J. Continuous cooperative development. Whitstable, UK: International Association of Teachers of English as a Foreign Language (IATEFL). 2002.

8. Mann S. Evaluation. In Harnisch \& Swanton (eds.), 2004; 113-129.

9. Mann S. The language teacher development. Cambridge University Press. 2005.

10. Farrell TSC. Reflective practice in an EFL teacher development group. Syst. 1999; 27: 157-172.

11. Van Manen M. The tact of teaching: the meaning of pedagogical thoughtfulness. Albany, NY: SUNY Press; London, Ont.: Aithouse Press. 1991.

12. Dewey J. How we think. New York: Dower Publications. 1973.

13. Freese AR. The role of reflection on preservice teachers' development in the context of a professional development school. Teach Teach Educ. 1999; 15: 895909.

14. Ho B, Richards JC. Reflective thinking through
In this study, it was tried to concentrate on general aspects of teacher professional development in the area of errors and error correction. Three experienced high teacher journal writing: Myths and realities. Prospect: $J$ Aust TESOL. 1993; 8: 7-24.

15. Freeman D. Teaching training, development, and decision making: a model of teaching and related strategies for language teacher education. TESOL $Q$. 1989; 23: 27-45.

16. Prawat R. Conversation with self and settings: a framework for thinking about teacher empowerment. Am Educ Res J. 1991; 28(4): 737-757.

17. Ur P. A course in language teaching: practice and theory. United Kingdom: Cambridge University Press. 2002.

18. Brown HD. Principles of language learning and teaching. New York: Longman. 2000.

19. Corpus VAFS. Error correction in second language writing: teachers' beliefs, practices, and students' preferences. Queensland Univ Technol. 2007.

20. Harmer $J$. The practice of english language teaching. London: Longman. 1998.

21. Richards JC, Lockhart C. Reflective teaching in second language classrooms. United Kingdom: Cambridge University Press. 1997.

22. Borg M. Teacher's beliefs. ELT J. 2001; 55(2): 186188.

23. Hyland K, Anan E. Teachers' perceptions of errors: the effects of first language and experience. Syst. 2006; 34: 509-519.

24. Lee I. Ten mismatches between teachers' beliefs and written feedback practice. ELT J. 2009; 63(1): 1322.

25. York-Barr J, Sommers WA, Ghere GS, Montie J. Reflective practice to improve schools: An action guide for educators. Corwin Press, Inc. 2001.

26. Williams M, Burden RL. What do teachers bring to the teaching-language process? In Psychology for Language Teachers: A Social Constructivist Approach. New York: Cambridge University Press. 2002; 46-64.

27. Tripp D. Critical incidence in teaching: developing professional judgment. London. Routledge. 1993.

28. Bailey $\mathrm{K}$. The processes of innovation in language teacher development: what, why and how teachers change. In Flowerdew et al. (eds.), 1992; 253-282.

29. Willis J, Willis D. (eds.). Challenge and change in language teaching. Oxford: Heinemann. 1996.

30. Allwright D. From teaching points to learning opportunities and beyond. TESOL Q. 2005; 39(1):9-31.

31. Prabhu NS. An interview with Alan Maley. Lang Teach. 2003; 27: 3-7.

32. James P. Teachers in action: tasks for in-service language teacher education and development. United Kingdom: Cambridge University Press. 2001.

33. Bowen T. Continuous professional development. Onestop Magazine._2004; 
http://www.onestopenglish.com/News/Magazine/Ar chive/continius.htm

34. Kumaravadivelu B. Language teacher education for a global society: a modular model for knowing, analyzing, recognizing, doing, and seeing. Routledge. 2012.

\section{Appendix}

Dear teacher

Please answer the following questions.

1. What are errors?

2. What are the sources of errors?

3. What are the aims of error correction?

4. Should all errors be corrected?

If yes, how? If no, which error should be corrected and how? Which ones should be ignored and why?

5. Do you think learners want their errors to be corrected? How do you know that?

6. Do you think learners will learn from error correction? How? When error correction is most helpful for them?

7. Which one do you prefer and use most? Implicit or explicit error correction. Why and why not the other one?

8. Which one do you believe in? Please explain.

a. Errors show insufficient knowledge and must be corrected whenever they occur.

b. Errors are signs of development.

9. Do you agree that the use of corrected forms by the learners depend on the correction that you provided and nothing more?

10. Have you ever thought about your manner of error correction? Explain.

11. Have you ever compared your manner of error correction with other teachers? If yes, what was the result(s)?

12. What are the sources of your knowledge about errors and error correction?

13. Did you consult any books or articles about this issue? If yes, can you name the sources?

14. Do you think your knowledge, belief and ideas about errors and error correction from the beginning years of your teaching up to now has changed? In what ways? Please explain detailfully. You can also write any anecdotes of interesting points you remember about errors and error correction.

15. Why did you change your ideas about this issue? (if there is any change)

16. Some years later, do you believe you will still hold the same ideas? Why do you think so?

\section{KURMANJ}

Copyright: (C) 2021 The Author(s); This is an open-access article distributed under the terms of the Creative Commons Attribution License (http://creativecommons.org/licenses/by/4.0), which permits unrestricted use, distribution, and reproduction in any medium, provided the original work is properly cited.

Citation: Mirsanjari Z, Aronaghi A. Errors and Teacher Professional Development. KURMANJ, 2021; 3(3): 5-18. 